\title{
Xantogranuloma Múltiplo do Adulto: Relato de Caso e Breve Revisão da Literatura
}

\author{
Felipe Siqueira Ramos ${ }^{1}$, Flávia Regina Ferreira ${ }^{2}$, Samuel Henrique Mandelbaum³, Fernanda da Rocha Gonçalves ${ }^{4}$ \\ 'Médico Especializando do $1^{\circ}$ ano de Dermatologia do Hospital Universitário de Taubaté - HUT/UNITAU - Taubaté-SP, Brasil \\ ${ }^{2}$ Mestre e Doutora em Ciências pela Universidade Federal de São Paulo -UNIFESP/EPM - Professora Assistente III da disciplina \\ de Dermatologia do Departamento de Medicina da Universidade de Taubaté / Médica do Serviço de Dermatologia do Hospital \\ Universitário de Taubaté - HUT/UNITAU - Taubaté-SP, Brasil \\ ${ }^{3}$ Especialista em Dermatologia - Professor Assistente da disciplina de Dermatologia do Departamento de Medicina da Universidade \\ de Taubaté/ Chefe do Serviço de Dermatologia do Hospital Universitário de Taubaté - HUT/ UNITAU - Taubaté-SP, Brasil \\ ${ }^{4}$ Especialista em Patologia - Médica Patologista Assistente do Hospital do Servidor Público Estadual - São Paulo-SP, Brasil
}

RESUMO - O xantogranuloma múltiplo do adulto é uma histiocitose de células não Langerhans, variante rara do xantogranuloma juvenil. A etiologia é desconhecida, afectando indivíduos adultos predominantemente abaixo dos 30 anos, sem predileção por gênero. Manifesta-se clinicamente como múltiplas pápulas ou nódulos amarelo-acastanhados disseminados. A confirmação diagnóstica se dá pelo exame anatomopatológico e pela imuno-histoquímica, que permitem ainda diferenciá-lo das histiocitoses de células de Langerhans. A involução espontânea é incomum. Relatamos um caso clássico, raro e clinicamente exuberante de xantogranuloma múltiplo do adulto e aproveitamos para realizar breve revisão da literatura sobre o tema.

PALAVRAS-CHAVE - Adulto; Doenças da Pele; Granuloma; Histiocitose de Células não Langerhans; Xantomatose.

\section{Multiple Adult Xanthogranuloma: Case Report and Brief Literature Review}

ABSTRACT - Multiple adult xanthogranuloma is a non-Langerhans cell histiocytosis, a rare variant of the juvenile xanthogranuloma. The etiology is unknown, affecting individuals predominantly below 30 years of age, without predilection for gender. Clinically presents itself as multiple, disseminated, yellow-brownish papules or nodules. Diagnostic confirmation is given by histopathology and by immunohistochemistry, which further allow to distinguish it from Langerhans cell histiocytosis. The spontaneous regression is uncommon. We report a classic, rare and clinically exuberant case of multiple adult xanthogranuloma and took the opportunity to perform a brief literature review on the topic.

KEYWORDS - Adult; Granuloma; Histiocytosis, Non-Langerhans-Cell; Skin Diseases; Xanthomatosis.

\section{INTRODUÇÃO}

O xantogranuloma múltiplo do adulto (XGMA) é uma variante rara do xantogranuloma juvenil, uma histiocitose não Langerhans que afeta predominantemente crianças. ${ }^{1,2} \mathrm{Ma}-$ nifesta-se clinicamente como múltiplas pápulas ou nódulos amarelo-acastanhados disseminados, em diferentes estágios evolutivos. ${ }^{2,3}$ Afecta indivíduos adultos predominantemente abaixo dos 30 anos, sem predileção por gênero. ${ }^{1,2}$ O objetivo deste relato é apresentar um caso clássico e clinicamente exuberante de XGMA, ressaltando a raridade desta variante clínica e realizar breve revisão da literatura.

\section{CASO CLÍNICO}

Paciente do gênero masculino, 60 anos, fototipo III,

Apresentaçōes e Prémios / Presentations and Prizes: Apresentado sob a forma de pôster na XXI Reunião Anual dos Dermatologistas do Estado de São Paulo (RADESP) - 03 a 05 de Novembro de 2016 - São Paulo-SP

Correspondência: Flávia Regina Ferreira

Rua Paraguai, 59 - Jardim das Nações

Taubaté-SP, Brasil, CEP: 12030-240

Email: dermagica@uol.com.b

DOI: https://dx.doi.org/10.29021/spdv.76.2.870
Recebido/Received

27 Dezembro/December 2017

Aceite/Accepted

17 Março/March 2018 


\section{Caso Clínico}

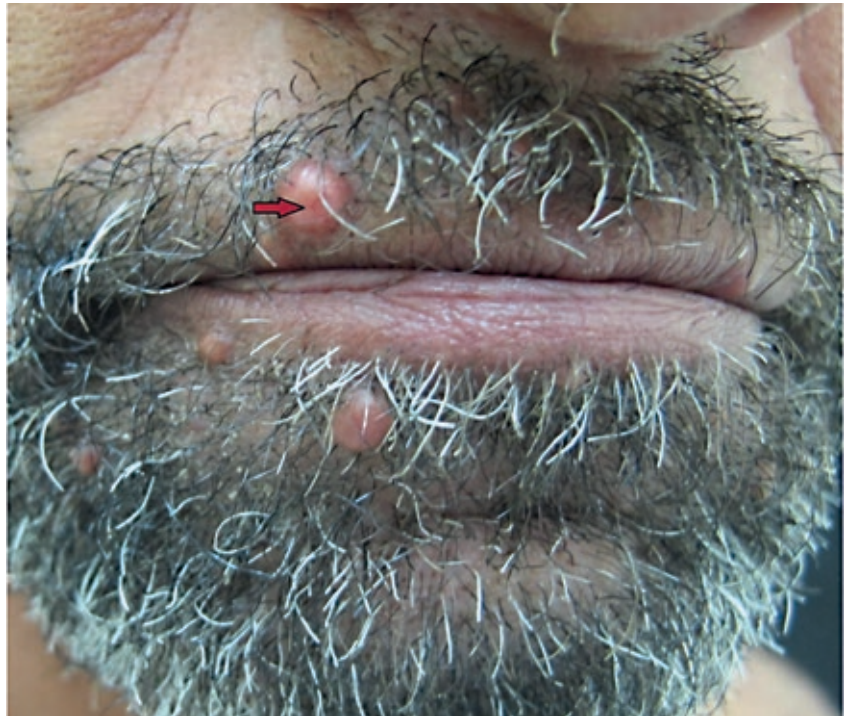

Figura 1 - Região perioral direita - pápulas eritêmato-amareladas e brilhantes. Lesão lábio superior - telangiectasia na superfície.

trabalhador rural, referindo desde há três meses o aparecimento progressivo de lesões arredondadas com início em áreas foto-expostas (não cobertas) e depois envolvendo todo o corpo; relatava terem sido precedidas de picadas de inseto.

Ao exame dermatológico, apresentava dispersas por todo tegumento: pápulas eritêmato-amareladas, brilhantes, de aproximadamente $0,5 \mathrm{~cm}$ de diâmetro, bem delimitadas e algumas com telangiectasias na superfície (Fig.s 1 e 2). Os exames laboratoriais recentes incluindo hemograma, provas de coagulação, proteinograma electroforético e lipidograma não evidenciavam alterações e as sorologias eram negativas para hepatite $\mathrm{B}$ e C. Procedeu-se então à biópsia excisional de uma das lesões, cujo exame anatomopatológico evidenciou: proliferação histiocitária nodular com linfócitos e escassas células

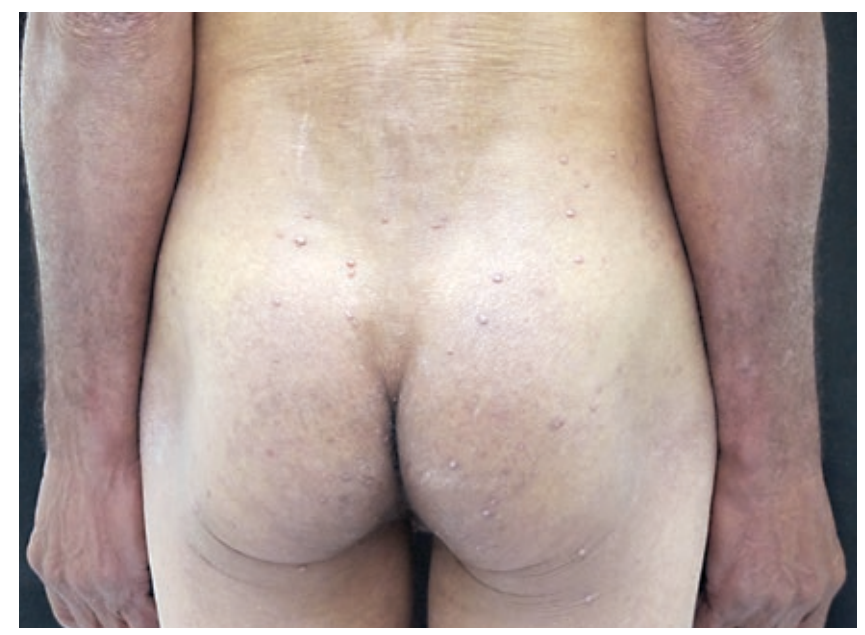

Figure 2 - Regiões lombar, glútea e posterior de coxa - múltiplas pápulas eritêmato-amareladas e brilhantes.

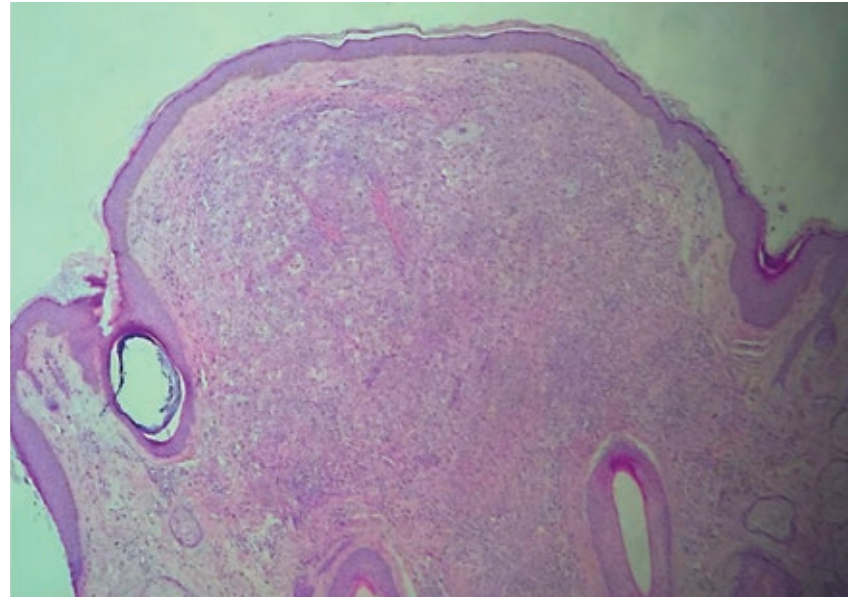

Figure 3 - Proliferação histiocitária difusa na derme superficial e profunda associada a infiltrado linfocitário (H\&E 40X).

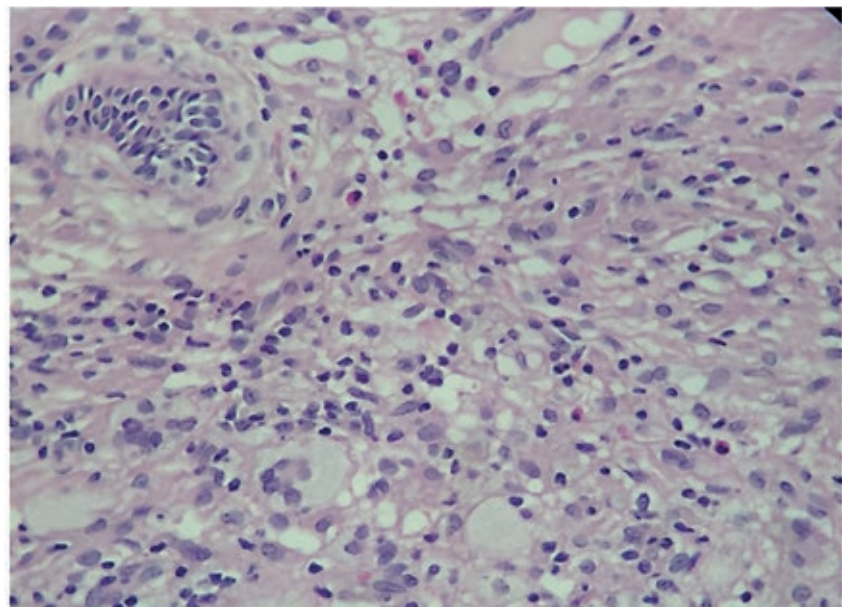

Figura 4 - Infiltrado histiocitário xantogranulomatoso com linfócitos, eosinófilos e células de Touton (H\&E 400X).

de Touton na derme superficial e profunda, compatível com xantogranuloma (Fig.s 3 e 4). O painel imuno-histoquímico revelou expressão de CD68 (Fig. 5) e factor XIlla, e ausência de imunoexpressão de marcadores de células de Langerhans (CDla e S100).

Face à clínica do paciente e aos resultados do estudo anatomopatológico e da imuno-histoquímica, fechou-se o diagnóstico de XGMA. Os exames de imagem solicitados para avaliação visceral, nomeadamente ultrassonografia de abdômen estavam dentro da normalidade. $O$ paciente foi encaminhado ao oftalmologista para investigação de possível comprometimento ocular, o qual resultou negativo. Após dois meses, as lesões apresentavam sinais de regressão (Fig. 6).

\section{DISCUSSÃO}

Gartmann e Tritsch, em 1963, descreveram pela primeira vez um caso de xantogranuloma no adulto. ${ }^{4}$ Desde então, e até 2016, apenas cerca de 25 casos de XGMA encontram-se 


\section{Caso Clínico}

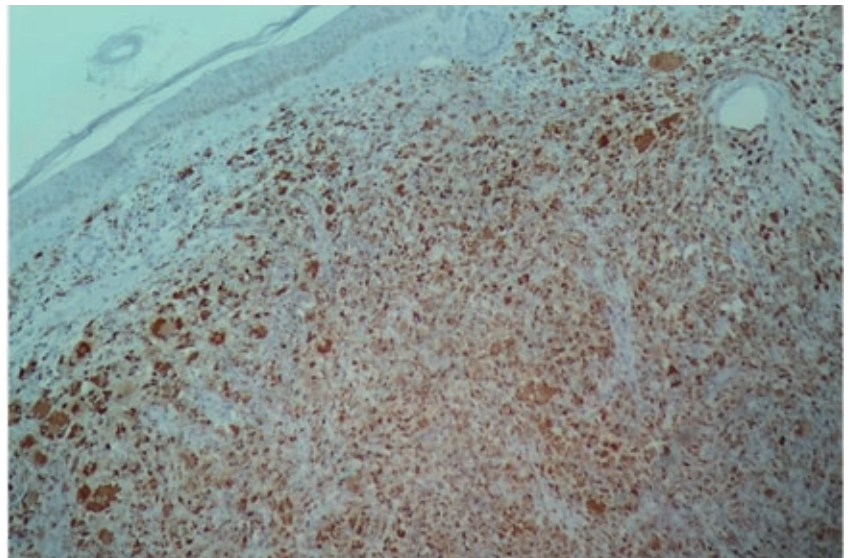

Figura 5 - Exame imuno-histoquímico revelando positividade das células para o marcador CD68 (100X)

descritos na literatura. ${ }^{5-7}$ O XGMA é uma histiocitose não Langerhans, variante de início tardio do xantogranuloma juvenil, de etiologia desconhecida, caracterizada pela proliferação de histiócitos, células de linhagem monocítico-macrofágica, que infiltram a pele e podem também afetar outros órgãos e tecidos. ${ }^{1-4,8} \mathrm{~A}$ etiologia é desconhecida. A ocorrência após infecções e estímulos físicos (picadas de inseto, traumas), conforme observado neste caso, é descrita na literatura e acredita-se seja uma resposta granulomatosa reativa dos histiócitos. ${ }^{2,9}$ As lesões geralmente iniciam-se como pápulas eritêmato-amareladas, firmes, assintomáticas, assimétricas, distribuindo-se predominantemente no tronco e extremidades, variando de alguns milímetros a vários centímetros de diâmetro. ${ }^{2,3,6,8}$ No adulto o envolvimento extracutâneo é excepcional, embora haja descrições de associação à anormalidades ou malignidades hematológicas (trombocitose essencial, leucemia linfocítica crônica, linfoma B de grandes células, síndrome mielodisplásica e gamopatia monoclonal) e mais raramente à neoplasia sólida (trato gastro-intestinal).5.7 $\mathrm{Na}$ forma juvenil, pode haver acometimento extracutâneo (cerca de $4 \%$ dos casos), principalmente ocular $(0,4 \%)$, com comprometimento da úvea, glaucoma e risco de hemorragia. ${ }^{1,3,4,6}$ Outras localizações extra-oculares já descritas para a forma juvenil, incluem: os pulmões, o fígado, os testículos, os rins e o sistema nervoso central. ${ }^{5,6}$ Alterações no perfil lipídico não são relatadas. ${ }^{1,2,5} \mathrm{~A}$ resolução espontânea pode ocorrer (meses a anos), embora seja incomum na variante clínica do adulto. ${ }^{3,5,8}$ Clinicamente, os principais diagnósticos diferenciais do XGMA incluem: molusco contagioso, criptococose, hanseníase virchowiana (hansenomas), histiocitose eruptiva generalizada, xantomas papulosos, xantomas tuberosos e neurofibromatose. ${ }^{2,9} \mathrm{O}$ exame histopatológico mostra um infiltrado celular dérmico composto por histiócitos, linfócitos, eosinófilos e, ocasionalmente, neutrófilos. ${ }^{8}$ Lesões mais antigas, apresentam células espumosas, que correspondem a histiócitos carregados de lipídios, além de células gigantes tipo corpo estranho e células de Touton. ${ }^{2-4,8} \mathrm{O}$ estudo imuno-histoquímico demonstra positividade para marcadores

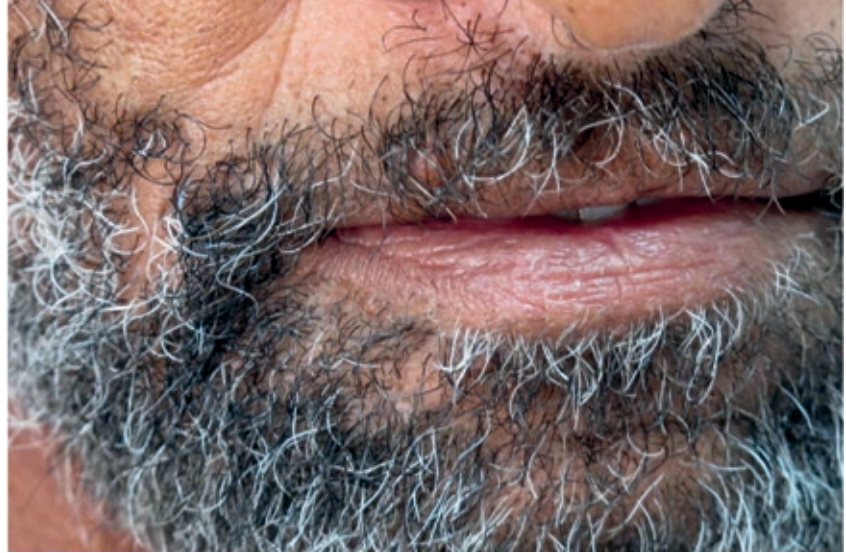

Figura 6 - Regressão espontânea das lesões.

de macrófagos (CD68 e HAM56), e também para marcador de dendrócitos dérmicos (FXIIla), enquanto marcadores de células Langerhans (CDla e S100) são negativos, o que permite diferenciar o XGMA das histiocitoses de células de Langerhans. ${ }^{2,3,8}$ As modalidades terapêuticas possíveis, incluem: a crioterapia localizada, o laser de $\mathrm{CO} 2$, a excisão das lesões maiores e o uso de retinóides orais. ${ }^{1-5,8}$ Quando da associação do XGMA com anormalidades hematológicas ou neoplasias há tendência à regressão com o tratamento da doença de base. 5,6 No paciente em questão, optou-se pela conduta expectante, uma vez que as lesões, aos 2 meses de acompanhamento, já apresentavam sinais de regressão.

Conflitos de interesse: Os autores declaram não possuir conflitos de interesse.

Suporte financeiro: $O$ presente trabalho não foi suportado por nenhum subsídio ou bolsa.

Confidencialidade dos dados: Os autores declaram ter seguido os protocolos do seu centro de trabalho acerca da publicação dos dados de doentes.

Protecção de pessoas e animais: Os autores declaram que os procedimentos seguidos estavam de acordo com os regulamentos estabelecidos pelos responsáveis da Comissão de Investigação Clínica e Ética e de acordo com a Declaração de Helsínquia da Associação Médica Mundial.

Consentimento dos Doentes: Obtido.

Conflicts of interest: The authors have no conflicts of interest to declare.

Financing Support: This work has not received any contribution, grant or scholarship.

Confidentiality of data: The authors declare that they have followed the protocols of their work center on the publication of data from patients.

Protection of human and animal subjects: The authors declare that the procedures followed were in accordance with the regulations of the relevant clinical research ethics committee and with those of the Code of Ethics of the World Medical Association (Declaration of Helsinki).

Patients consent: Obtained. 


\section{Caso Clínico}

\section{REFERÊNCIAS}

1. Silveira DP, Goldoni BA, Althoff GC, Solano Junior P, Ely PB. Xantogranulomas múltiplos do adulto: relato de caso e revisão da literatura. Arq Catarin Med. 2014; 43:101-3.

2. Caro-Bisso KE, Castillo-Farneschi W, Chian-García C. Xantogranuloma múltiple del adulto: reto diagnóstico y terapêutico. Dermatol PERU. 2013; 23: 43-6.

3. Navajas B, Eguino P, Trébol I, Lasa O, Gardeazábal J, Díaz-Pérez JL. Xantogranuloma múltiple del adulto. Actas Dermosifiliogr. 2005; 96:171-4.

4. Achar A, Naskar B, Mondal PC, Pal M. Multiple generalized xanthogranuloma in adult: case report and treatment. Indian J Dermatol. 2011; 56:197-9.
5. Vadeboncoeur S, Provost N. Multiple Xanthogranulomas in an adult: known entity, new association. J Cutan Med Surg. 2016; 20:474-7.

6. Ederle A, Kim KH, Gardner JM. Eruptive xanthogranuloma in a healthy adult male.

7. J Cutan Pathol. 2016 (in press).7. Namiki T, Miura K, Yokozeki H. Multiple CD 163(+) adult xanthogranuloma associated with myelodysplastic syndrome. J Dermatol. 2015; 42:1106-7.

8. Tan LC, Aw CW. Unusual presentation of adult xanthogranuloma. Singapore Med J. 2014; 55:e25-e27.

9. Saad N, Skowron F, Dalle S, Forestier JY, Balme B, Thomas L. Multiple adult xanthogranuloma: Case report and literature review. Dermatology. 2006; 212:73-6. 